\title{
Allometric scaling of Microbial Fuel Cells and stacks: the lifeform
}

\author{
case for scale-up \\ John Greenman* and Ioannis A. Ieropoulos \\ Bristol BioEnergy Centre, Bristol Robotics Laboratory, University of the West of England, \\ Frenchay Campus, BS16 1QY, UK \\ *Corresponding author: john.greenman@uwe.ac.uk
}

\begin{abstract}
This case study reports for the first time on the comparison between allometric scaling of lifeforms and scale-up of microbial fuel cell entities; enlarging individual units in volume, footprint and electrode surface area but also multiplying a static size/footprint and electrode surface area to scale-up by stacking. A study published in 2010 by DeLong et al. showed for the first time that Kleiber's law does not apply uniformly to all lifeforms, and that in fact growth rate for prokaryotes is superlinear, for protists is linear and for metazoa is sublinear. The current study, which is utilising data from previous experiments, is showing for the first time that for individual MFC units, which are enlarged, growth rate/power is sublinear, whereas for stacks this is superlinear.
\end{abstract}

\section{Introduction:}

On the planet as a whole there are many different environments producing primary biomass (trees, forests, grasslands, marine macroalgae, algal blooms on lakes and at sea etc) so there is no shortage of primary biomass, that ultimately gets broken down and transformed into new secondary biomass by the various life-forms that eat the plants, or eat the plant-eaters. 
The end result of all the food chains is (ultimately) wet biomass (sludges) formed via heterotrophic bacteria, which degrade, putrefy and otherwise break down and recycle organic matter; into more sludge and $\mathrm{CO}_{2}$.

\subsection{Organic fuel:}

The classic pathway (discounting undersea hot vents) for the production of all biomass on the planet is (1) photosynthesis by marine and terrestrial photosynthetic species of bacteria, algae and plants, and then (2) a complex web of food chains to become (eventually) organic biomass in suspension (biomass soup). Biomass soup consists of insoluble and soluble fractions of organic matter mixed together. This includes both soluble BOD/pollutant fractions (e.g. urine) as well as insoluble organic detritus as fine particle suspensions (e.g. sludge's, run-offs, sewage, brewery waste, agricultural waste); in all cases the material is too-wet-to-burn and will give a net energy loss if it was to be dried and combusted. Yet, for the planet as a whole there is no shortage of such "biomass soup" and it represents a huge amount of un-tapped energy. Indeed there is thought to be more generated each year by the planet as a whole than there are fossil fuels drilled out of the rocks. Therefore, a technology that can efficiently utilise wet biomass to produce energy may be of central importance in the future of the planet if it is ever going to be weaned off fossil fuels. Such a technology includes microbial fuel cells (MFC). For MFC there is no shortage of fuel, yet it is all derived from the "immediate carbon cycle" rather than through the "fossil fuel carbon cycle". In addition to their power outputs, MFC's produce carbon dioxide (from C/E substrate oxidation by electron abstraction) and biomass, and they can be configured to maximise the rate of feedstock uptake, utilisation and transformation into new biomass and subsequent re-cycling of elements (at the anode), and the production of water, peroxide or biocidal 
solutions from the cathode; all of these are dependent on the growth rate and metabolic rate of the microbes that colonise the electrodes.

\subsection{Microbial Fuel Cell designs:}

There are many different types of design of Microbial Fuel Cell described in the literature. All have anodes and cathodes but the latter may be open-to air with or without a cathodic chamber. Some are tubular with the cathode on the outside whilst some are tubular with the cathode on the inside $[1,2]$. All types have anodes contained within anodic chambers. From first principles regarding the importance of reducing proton migration, the anodes and cathodes should be as close as possible to each other, at either side of a membrane (PEM) or "interface" in the case of membrane-less systems. In general, small scale MFC have been shown to be more power dense than large-scale systems [3] due to more favourable surface area to volume (SA/V) ratios [4]. For small scale MFC, configuring a plurality of units into stacks performs scale up. However, there are exceptions for the scale-up of tubular or elongated designs where an increase in just one of the dimensions e.g. length can be made, where power density per unit of length remains the same; so absolute power is approximately in proportion to length [4]. However, a single MFC, whatever its size or shape, can only produce electrical power at a low voltage (e.g. 0.5-0.6 V), so a stack of at least two or more MFC units, connected in series is required to step-up the low voltage output to one that can be used to power various applications that usually require voltages well over 1V. [5].

\subsection{Allometric laws:}

Allometric laws are scaling laws that deal with the measurement and comparison of the relationship of scale to the parameters of a system, revealing scale invariant quantities. In physics, scaling laws typically reflect underlying generic features and physical principles and are independent of detailed dynamics and specific characteristics. Therefore, scaling also has 
relevance for biology, particularly for comparing the relationship of body size/mass, to different biological parameters. In general, the smaller the size of the particular species of living cell, then the faster the growth and the higher the metabolic rate. This is also true of multicellular structures such as metazoan plants and animals. Oak trees are less productive than grass species, and elephants "grow" much more slowly than mice [6]. The same is true at the unicellular level for free living single celled microbes [7]. The smallest photosynthetic cell species (prokaryotic microalgae) grow faster than any other type of metazoan plant species, which explains why algal biomass is many times more productive than all other forms of photosynthetic life for primary biomass production, (and as a consequence is most likely to be the option of choice for all future biofuel production). Nevertheless, algal growth rates are still relatively slow compared to heterotrophic bacteria, the fastest of which has a mean generation time (the average time that a cell splits into two) of as little as 10 minutes compared to the equivalent 1-2 days for microalgae.

The classical allometric equation was formulated by Otto Snell in 1892 [8], and is given below:

$Y=Y_{0} \cdot M^{\mathrm{b}}$

This can be re-written as: $\log Y=b \log M+\log Y_{0}$

Where $\mathrm{Y}=$ dependent parameter (metabolic rate or growth rate or reaction rate)

$\mathrm{Y}_{0}=$ the integration constant

$M=$ body mass (or size of lifeform)

$\mathrm{b}=$ scaling exponent

\subsection{Kleiber's law:}


Scaling equations were first applied in biology from knowledge of metabolic rates and body mass for a wide range of animals by Kleiber [6] who showed that metabolic rate (B) relates to body mass $(M)$ with a metabolic exponent ' $b$ ' of $\approx 3 / 4$ and this relationship became known as Kleiber's law: 'b' $\propto \mathrm{M}^{0.75}$

However, DeLong et al. [7] have found that the scaling of metabolism is not universal for all forms of life and is sublinear $(b<1)$ for metazoan, linear $(b=1)$ for protists, and superlinear $(b>1)$ for prokaryotes.

\subsection{Efficiency of biomass production:}

The efficiency of biomass production (E) can be expressed [7] as the rate of biomass production (gram weight) divided by the rate of metabolism (in Joules), when both are standardized as per unit of body mass, in units of gram weight per Joule $\left(\mathrm{gJ}^{-1}\right)$.

$\mathrm{E}=\mu_{\max } /(\mathrm{B} / \mathrm{M})$

Where $\mu_{\max }=$ maximum specific growth rate (units, $\mathrm{h}^{-1}$ )

$\mathrm{B}=$ the metabolic rate (in Joules), and $\mathrm{M}=$ body mass $(\mathrm{g})$.

In this paper, we consider or treat MFCs and stacks of MFCs as multicellular life-forms (i.e. the equivalent of metazoan creatures) and attempt to compare their mass and metabolic power by superimposing data points on the rates of growth/metabolism versus mass "continuum" graph described in detail by DeLong et al. [7], which have been used as the control for the 'landscape'. The data have been processed from published work from our laboratory over the last decade, and have been organised into groups, detailed in Materials and Methods below. Naturally, the MFC types and the experimental conditions in these previously published articles vary from one another, however the comparison of size vs power has been done for units in distinct groups, members of which share similarities of 
feature e.g. cathode type, feedstock, architecture, use of ceramic or polymeric PEM. The ultimate aim of this work is to apply allometric scaling as a means of comparing different types of MFC running across a wide range of different conditions and predict by extrapolation the likelihood of success when units or boxes are scaled-up to produce higher amounts of continuous power (e.g. 1 to $10 \mathrm{~W}$ ).

\subsection{Materials and Methods}

\subsection{MFC types}

\subsubsection{Monoculture (Group 3 on figures)}

Shewanella oneidensis (strain MR-1) was grown in standard $20 \mathrm{~mL} /$ side two-chamber MFCs fabricated via rapid-prototyping [9] with $270 \mathrm{~cm}^{2}$ plain carbon veil electrodes [10]. Replicates (n=8 MFC) were inoculated with S. oneidensis MR-1 and fed with modified M1 minimal medium (based on [11]) with $18 \mathrm{mM}$ sodium-DL-lactate as the sole carbon source. The medium was perfused continuously, initially at a low flow rate of $7.2 \mathrm{~mL} \mathrm{~h}$ until the anodic biofilm had matured and reached dynamic steady state where electrode readings and concentrations of daughter cells (cfu mL $\mathrm{m}^{-1}$ ) were constant (approximately 3 weeks). Subsequently, the flow rate was changed to $14.5,27.3,50.8,72.6$ and $94.4 \mathrm{~mL} \mathrm{~h}^{-1}$ and the effects on steady-state cell and power production levels determined at each flow. All experiments were conducted at room temperature $23 \pm 2^{\circ} \mathrm{C}$.

\subsubsection{Mixed culture MFCs (Groups 2, 4-8 on figures)}

All mixed culture MFC were inoculated from highly diverse ecological mixes taken from wellestablished MFC working successfully within the laboratory: These were in turn originally derived from sewage sludge for MFC designed for neutral-acid pH of feedstock or developed from sludge + urine mix for MFC designed to treat urine or alkaline waste. It is thought that 
once an ecological mix has established around the electrode, the biofilm remains ecologically stable thereafter, unless exposed to more extreme environmental conditions.

In addition to the $2 \times 20 \mathrm{ml}$ type of MFC described in 2.1.1, lighter weight variants (Group 2) were constructed with open-to-air cathodes, and in some designs the PEM membrane was replaced with ceramic membranes. The smallest MFC included a $1 \mathrm{ml}$ anodic volume, whilst the largest was $50 \mathrm{ml}$, with body masses between 6.6 and $82 \mathrm{~g}$.

Group 4 is our small, medium and large comparison, of conventional MFCs (from [3]). Group 5 is based on tubular MFCs made out of Nafion® tube, and includes 2 distinctly different levels of performance from the same MFC, based on maturity.

\subsubsection{Stacks of ceramic based or membrane-less MFC}

Group 6 is a comparison between a single Nanocure ${ }^{\circledR}$ MFC and a stack of 48 such units, all identical to the ones used on EcoBot-III [18].

Group 7 data is based on a terracotta cylindrical design MFC and is shown on figure 2 as a single unit MFC, and a single box of $\mathrm{n}=22$ identical units with masses of $97.6 \mathrm{~g}$ and $4.15 \mathrm{~kg}$ respectively.

Group 8 data (previously unpublished data) shows mass and power outputs from a membrane-less MFC system, where $\mathrm{n}=21$ units in one "small box" (lower blue point on figure) and $\mathrm{n}=38$ units in one "large box" (upper blue point).

\subsection{Data measurements}

The body mass of all MFC (including their liquid contents) was obtained by measurement of their total weights (including fluid weight) using a laboratory weighing balance. For each type of MFC (Table 1), the electrical load applied to the circuit to ensure maximum power transfer was obtained from knowledge of internal resistance determined by polarisation experiments [12]. All MFC were run under constant flow conditions and power outputs 
(expressed as absolute units [13]) were measured continuously during steady state conditions.

\section{[TABLE 1 Inserted at this point in the text]}

\section{Results and Discussion:}

Group 1 data (figure 1) show the wide range of body mass and power output data for living cells (prokaryotes, protists and metazoans) described by DeLong et al. [7]. Their work included 355 examples of different species or conditions with mass and metabolic power output crossing nearly 16 orders of magnitude including both active/fed conditions $(\mathrm{n}=$ $167)$ as well as inactive, starved or endogenous conditions $(n=188)$. However, for the sake of clarity, their results (Group 1 data) are represented by just four main points, from the smallest to the largest of each of the three categories (prokaryotes, protists and metazoans) using points that fall on the scaling slopes and intercept lines that these workers obtained (using nested ANOVA). In comparison, the data points collected from MFC includes a total of $\mathrm{n}=20$ different conditions where both mass and power output were determined. All the MFC sizes that were studied were well into the size range of metazoans, being between $0.124 \mathrm{~g}$ to $12,600 \mathrm{~g}$ (Figure 2 ).

Group 2 data show a range of different types of MFC, some being "air-breathing" type, some made from polymeric composites (nanocure), but some using ceramic membranes. These illustrate the general trend reported previously [3] that increasing MFC vessel size (and thus its body weight) may give rise to higher absolute power, but in disproportion to its mass; this is why Group 2 data in Figure 2 appear to negatively sub-linear as power density decreases with size. 
Group 3 data are taken from a fixed size MFC using Shewanella species monoculture [9] and shows the effects of limiting supply rate of fuel (lactate) by changing flow rate/dilution rate. In this type of "perfusion biofilm MFC" changes in the supply rate clearly limited both metabolic rate $(\mathrm{W})$ and growth rate $(\mu)$ in strict proportion, showing that at moderate to high supply rates, the link between catabolism and anabolism within the cell is strongly coupled. This is not thought to be the case for the biofilm cells in batch culture during stationary phase and/or where C/E is in excess and other elements limit the growth, where "energy-spilling reactions" occur in order to re-oxidise NADH within the cells and maintain the intracellular redox balance ratio of $\mathrm{NAD}^{+} / \mathrm{NADH}$.

Ledezma et al. [9] also includes empirical measurements of specific growth rate at each steady-state flow rate, allowing for determination of the species maximum specific growth rate $\left(\mu_{\max }\right)$ under the particular MFC conditions. The $\mu_{\max }$ was shown to be $0.827 \pm 0.004 \mathrm{~h}^{-1}$ which is equivalent to values obtained for E. coli growing aerobically in a chemostat [14-15]. The potential for Shewanella to grow even faster may be achieved by increasing temperature (e.g. from $20^{\circ} \mathrm{C}$ to $37^{\circ} \mathrm{C}$ as used for E. coli) or by making other changes in the microenvironmental physicochemical conditions. Only by mapping the effects of all main physicochemical parameters (mainly $\mathrm{pH}, \mathrm{pO}_{2}$, dilution rate, concentration of macro- and micronutrients, water activity, redox and presence of toxic compounds) would it be possible to determine the optimum settings to give an ideal physiological state with the highest $\mu_{\max }$ values possible, described as maximum $\mu_{\max }$ (or max- $\mu_{\max }$ for short). 
The findings also show that oxidation by electron abstraction at an anode can be just as efficient as aerobic sparge and/or aeration by mixing (which are both energy dependent processes employed within a bioreactor or chemostat). Although new biomass production represents a potential loss of energy from the system (i.e. the calorific energy content of the shedding cells) it is important as a means of recycling elements, and in a scaled-up cascade system the new cell progeny can be re-utilised as an additional fuel feedstock by subsequent MFC downstream in the cascade $[16,17]$ thus minimising biomass production if required.

When C/E supply rate is limiting growth rate, the power output and specific growth rate are strongly coupled [9], which is generally the case for microorganisms in carbon-energy limited growth conditions. It should be noted that in conditions where C/E is in excess, growth is limited by the supply rate of some other element class of nutrient (e.g. N, P, K, S or essential micronutrient) and in these conditions catabolism is not thought to be tightly linked to anabolism, and the cell biomass per unit of energy decreases.

Efficiency: For our example (Shewanella), $\mu_{\max }=0.827$ per hour; $\mathrm{B}_{\max }$ (maximum metabolic rate per hour; power output from the $\mathrm{MFC}$ ) $=4.5 \mathrm{~J}$, and the weight of $\mathrm{MFC}=40 \mathrm{~g}$. The efficiency $=8.9 \mathrm{gJ}^{-1}$ which is in-line with lifeforms of similar mass [7].

Group 4 data show a comparison of three sizes of single MFC units, small, medium and large (taken from [3]). The relationship is clearly sub-linear, that is, power density decreases with increase of size of a single unit. 
Group 5 is based on small-scale $(124 \mu \mathrm{L})$ tubular MFCs made out of Nafion $\AA$ tube $[18,19]$, and includes 2 distinctly different levels of performance from the same MFC, based on maturity.

Group 6 is a comparison between a small volume $(1 \mathrm{~mL})$ pipette tip converted MFC, a single Nanocure® MFC and a stack of 48 such units, all identical to the ones used on EcoBot-III [20]. The scale-up from one Nanocure $₫$ MFC to 48 units is close to linear.

Group 7 data show scaling from one to 22 units in a single box, using ceramic MFC. Scaling appears to be superlinear, and to date these appear to be the most powerful MFC stacks developed. Group 8 shows laboratory data from a membrane-less MFC system where $\mathrm{n}=21$ units in one "small box" (lower point) and n= 38 units in one "larger box" (upper point). The slope of the regression line is slightly superlinear.

In this paper, we consider the MFC as a multicellular animal or plant (i.e. metazoan creature) but one which consists of prokaryotic microbes as the actively growing entity of this biohybrid. In this context, the MFC is the only technology, which allows exploitation of the highly efficient prokaryotic growth and metabolism but through embodiment, extends this to the metazoan scale. It is therefore extremely interesting to compare its mass and metabolic power in terms of other biological life forms such as prokaryotes, protists and metazoans. MFCs have previously been used to "energise" robots (e.g. EcoBot series of Symbots) [20], and this is bio-hybridisation at a different level, so treating the MFC devices as a multicellular creature, using allometric principles, is indeed an interesting approach. 
In addition to power outputs, MFC's produce carbon dioxide (from C/E substrate oxidation) and also utilise, transform and re-cycle elements by producing new biomass. It should be noted that in the absence of alternative electron acceptors (oxygen/sulphate/nitrate etc) the daughter cells cannot respire and cells will rapidly loose their metabolic energy due to lack of NADH re-oxidation. What is clear from Group 2 and Group 3 data is that the power output, utilisation of feedstock and new biomass production depends critically on the microenvironmental physicochemical conditions as well as on the species or type of organisms involved.

Within a prokaryotic cell, the main respiratory and photosynthetic components (enzymes, cytochromes, chlorophyll pigments) are all membrane bound. Examples are the thylakoid membranes of Cyanobacteria, and the membrane-bound respiratory complex, found in all species of life. It is the surface area of membrane that dictates the degree of metabolism (measured as activity per unit area) that can take place. As a cell gets larger in volume, surface area starts to constrain metabolism since the surface area reactions and interactions have to serve an increasing volume of total cell. If the volume becomes larger, the surface area available for biotransformations is lower in proportion since volume increases with regard to the radius cubed $\left(r^{3}\right)$ whilst the surface area increases by the radius squared $\left(r^{2}\right)$.

As previously stated, when body mass/size increases, then so does the metabolic rate, but not always in strict proportion to the mass, being highly superlinear for prokaryotes and close to linear for protists. For metazoans it is sub-linear, and this appears to be the case when considering the sizes of individual MFC of the same body-mass range. However, when stacks are scaled up by addition of "isolated" boxes (i.e. groups of identical/replicate units), 
then the data suggests that adding more units of the same design together shows a better than linear relationship, suggesting that collective units may somehow help stabilise outputs and improve units that may be underperforming. Providing the scaling relationship remains at least linear with stack unit number, then it suggests that large stacks could be constructed from a multiplicity of small MFC units, without loss of efficiency or power, for power outputs well above 1W. The log mass-log power plots from experimental MFC are a convenient way to compare different designs, different conditions of running, and different sizes of units or stacks, allowing for a realistic extrapolation to be made for power outputs and stack "footprint" size (mass or area-volume) for much larger scale projected systems. In theory the method could be used to compare published work regarding MFC and stacks designed or prototyped by other groups of workers from around the world. However, it would rely on workers reporting their outputs in absolute units of power (W per MFC unit) rather than relative power density, and most authors do not report the mass of their systems, making allometric comparisons very difficult if not impossible.

\section{Conclusions:}

Scale-up by increasing the size/volume of individual MFCs is shown to be sub-linear with decreasing power output per unit of mass. This is particularly demonstrated by the data in Group 2, which appear to have a negative sub-linear relationship. However, increasing the size of a stack by increasing the numbers of individual units, as a means to scale-up, shows linear or slightly super-linear increases in power output as the total stack size increases. Allometric analysis suggests that in the future, perhaps the best way for producing higher power (and indeed higher utilisation of feedstock waste) will be to make MFCs as small as 
possible, subject to application requirements, whilst maintaining high supply rates of fuel, and simply increasing the numbers of such units to form efficient stacks.

\section{Acknowledgements:}

The Authors would like to thank Drs Xavier Walter, Jiseon You, Majid Taghavi, Irene Merino Jimenez (all BBiC staff in general), as well as Dr Pablo Ledezma for access to experimental data. 
Figure 1: Metabolic rate and body mass for a range of life-forms, MFCs and MFC-stacks The dashed line shows linear slope for comparison of super- or sub- linear gradients

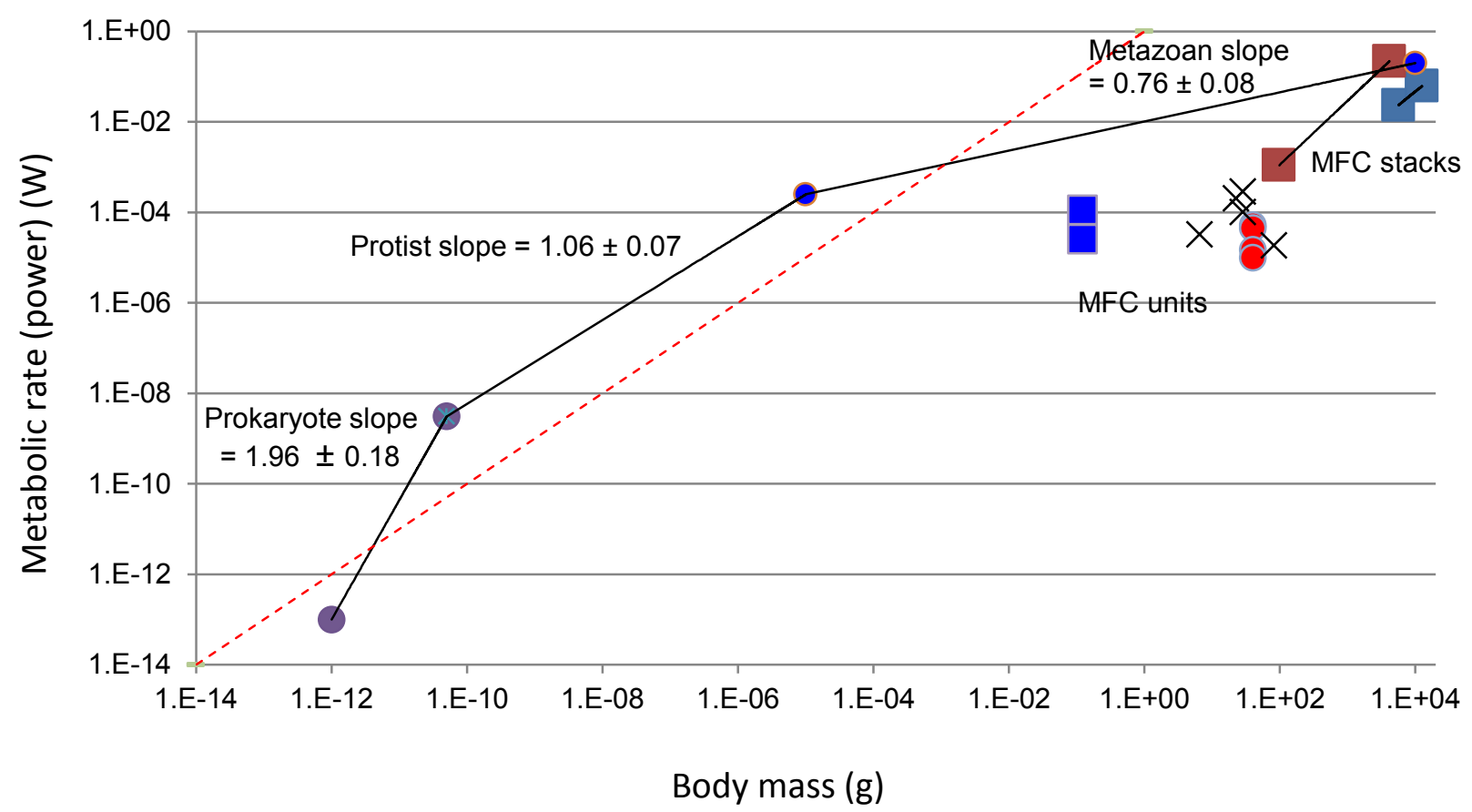

Figure 2: Allometric scaling for MFC (individual units and stacks)

The dashed line shows linear slope for comparison of super- or sub- linear gradients

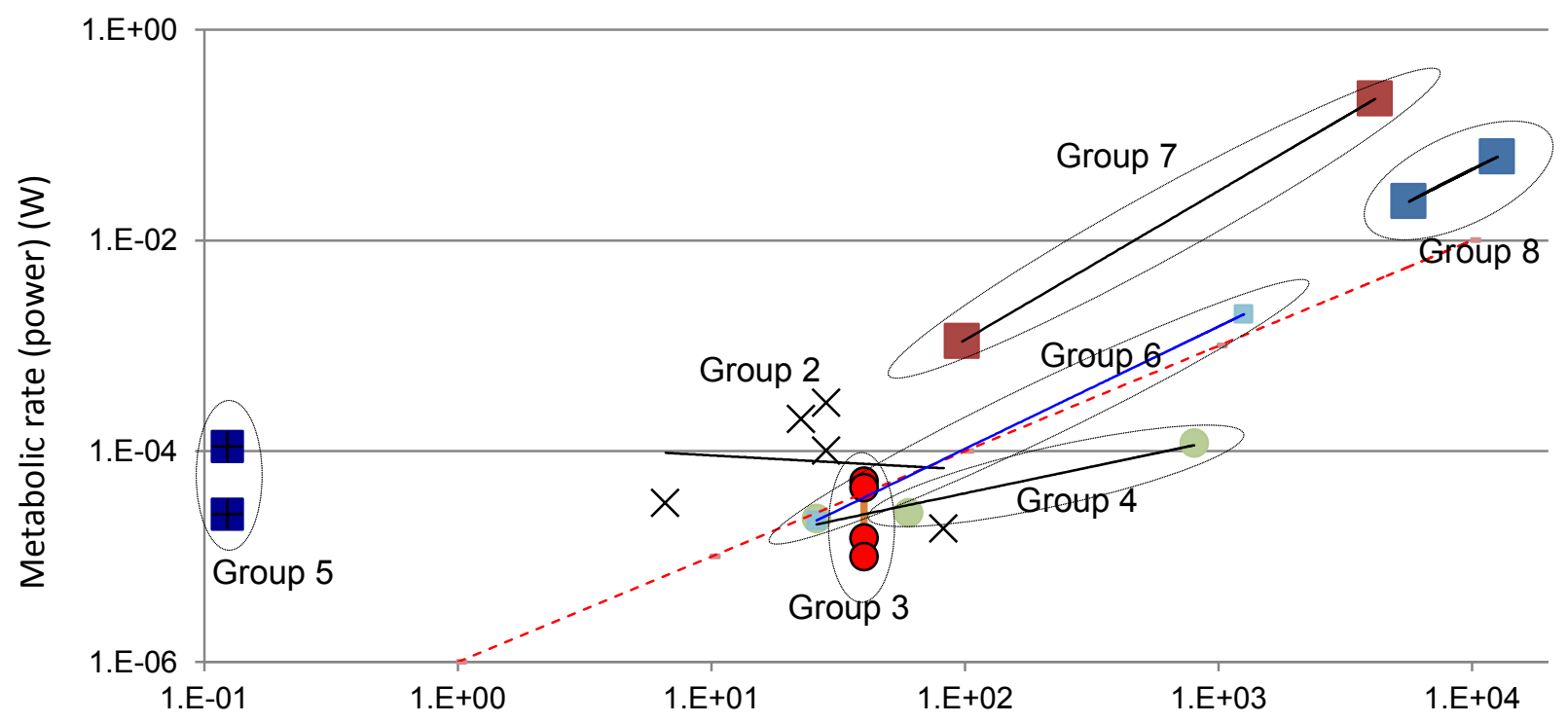

Body mass (g) 


\section{References}

1. Gajda I, Greenman J, Melhuish C, Ieropoulos IA (2016). Electricity and disinfectant production from wastewater: Microbial Fuel Cell as a self-powered electrolyser. Scientific Reports, 6: 25571.

2. Ieropoulos IA, Ledezma P, Stinchcombe A, Papaharalabos G, Melhuish C, Greenman J (2013). Waste to real energy: the first MFC powered mobile phone. Physical Chemistry Chemical Physics, 15, 15312-15316.

3. Ieropoulos, IA, Greenman J and Melhuish C (2008). Microbial fuel cells based on carbon veil electrodes: Stack configuration and scalability. International Journal of Energy Research, $32,1228-1240$.

4. Walter XA, Forbes S, Greenman J and Ieropoulos IA (2016). From single MFC to cascade configuration: The relationship between size, hydraulic retention time and power density. Sustainable Energy Technologies and Assessments, 14, 74-79.

5. Ieropoulos IA, Stinchcombe A, Gajda I, Forbes S, Merino-Jimenez I, Pasternak G, SanchezHerranza D and Greenman J (2016). Pee power urinal - microbial fuel cell technology field trials in the context of sanitation. Environ. Sci.: Water Res. Technol., 2, 336-343.

6. Kleiber, M. (1932). "Body size and metabolism". Hilgardia 6: 315-351. 
7. DeLong JP, Okie JG, Moses ME, Silby RM, Brown JH (2010). Shifts in metabolic scaling, production, and efficiency across major evolutionary transitions of life: PNAS, 107, 1294112945.

8. Snell 0. (1892). Die Abhängigkeit des Hirngewichts von dem Körpergewicht und den geistigen Fähigkeiten. Arch. Psychiatr. 23, 436-446.

9. Ledezma P, Greenman J and Ieropoulos I (2012). Maximising electricity production by controlling the biofilm specific growth rate in microbial fuel cells. Bioresource Technology 118, 615-618.

10. Melhuish C, Ieropoulos I, Greenman J and Horsfield I (2006). Energetically autonomous robots: Food for thought. Autonomous Robots, 21, 187-198.

11. Myers CR, Nealson KH (1988). Bacterial manganese reduction and growth with manganese oxide as the sole electron-acceptor. Science, 240, 1319-1321.

12. Ieropoulos I, Greenman J and Melhuish C (2010). Improved energy output levels from small-scale Microbial Fuel Cells. Bioelectrochemistry, 78, 44-50.

13. Ieropoulos, I., Winfield, J., Greenman, J. and Melhuish, C. (2010) Small scale microbial fuel cells and different ways of reporting output. ECS Transactions, 28 (9), 1-9. 
14. Senn H, Lendenmann U, Snozzi M, Hamer G, Egli T (1994). The growth of Escherichia coli in glucose-limited chemostat cultures: a re-examination of the kinetics. Biochim Biophys Acta; $1201(3):$ 424-436.

15. Kovárová K, Zehnder AJB, Egli T (1996). Temperature-dependent growth kinetics of Escherichia coli ML30 in glucose-limited continuous culture. J Bacteriol 178: 4530-4539.

16. Winfield J, Ieropoulos I and Greenman J (2012). Investigating a cascade of seven hydraulically connected microbial fuel cells. Bioresource technology 110, 245-250.

17. Ledezma P, Stinchcombe A, Greenman J, Ieropoulos I (2013). The first self-sustainable microbial fuel cell stack Physical Chemistry Chemical Physics 15 (7), 2278-2281

18. Taghavi, M., Greenman, J., Beccai, L., Mattoli, V., Mazzolai, B., Melhuish, C. and Ieropoulos, I. A. (2014). High-Performance, Totally Flexible, Tubular Microbial Fuel Cell. ChemElectroChem 1: 1994-1999.

19. Taghavi M, Stinchcombe A, Greenman J, Mattoli V, Beccai L, Mazzolai B, Melhuish C and Ieropoulos I (2015). Self-sufficient wireless transmitter powered by foot-pumped urine operating wearable MFC. Bioinspiration \& Biomimetics, 11 (1). 016001.

20. Ieropoulos I, Greenman J, Melhuish C, Horsfield I (2010) EcoBot-III-A Robot with Guts. ALife Proceedings 2010, 733-740. 
21. You, J., Walter, X. A., Greenman, J., Melhuish, C., Ieropoulos, I. (2015). Stability and reliability of anodic biofilms under different feedstock conditions: Towards microbial fuel cell sensors. Sensing and Bio-Sensing Research, 6, 43-50.

22. You, J., Greenman, J., Melhuish, C., Ieropoulos, I (2016a). Electricity generation and struvite recovery from human urine using microbial fuel cells. Journal of Chemical Technology and Biotechnology, 91(3), 647-654.

23. You, J., Preen, R.J., Bull, L., Greenman, J., Ieropoulos, IA. (2016b). 3D printed components of microbial fuel cells: Towards monolithic microbial fuel cell fabrication using additive layer manufacturing. Sustainable Energy Technologies \& Assessments, 19, 94-101.

24. Walter, X.A., Stinchcombe A, Greenman J and Ieropoulos IA (2017). Urine transduction to usable energy: A modular MFC approach for smartphone and remote system charging. Applied Energy, 192, 575-581. 


\section{Figure legends:}

Figure 1: Metabolic rate and body mass for a range of life-forms, MFCs and MFC-stacks The dashed line shows linear slope for comparison of super- or sub- linear gradients

Figure 2: Allometric scaling for MFC (individual units and stacks)

The dashed line shows linear slope for comparison of super- or sub- linear gradients

\section{Table legend:}

Table 1: Description of groups used for construction of figures in terms of geometry, materials, membrane, cathode-type, feedstock, biocatalyst and mass of units or stacks of MFC (with exception of Group 1, which refers to De Long et al. (2010) data) 


\begin{tabular}{|c|c|c|c|c|c|c|c|}
\hline System & Geometry/material & Membrane & Cathode-type & Feedstock & Biocatalyst & Mass (g) & Reference \\
\hline \multicolumn{8}{|c|}{ Group 1 } \\
\hline Lifeforms & na & na & na & na & & $10^{-12}-10^{4}$ & [7] \\
\hline \multicolumn{8}{|c|}{ Group 2} \\
\hline Single MFC & Spherical MFC/Nanocure ${ }^{\circledR}$ & CEM & $\begin{array}{l}\text { Re-circulated } \\
\text { aerated water }\end{array}$ & $\begin{array}{l}\text { Peptone yeast } \\
\text { extract }\end{array}$ & $\begin{array}{l}\text { Complex mixed } \\
\text { culture }\end{array}$ & 6.6 & $\begin{array}{l}\text { Unpublished } \\
\text { data }\end{array}$ \\
\hline Single MFC & Spherical MFC/Nanocure ${ }^{\circledR}$ & CEM & $\begin{array}{l}\text { Air-breathing } \\
\text { (MPL) }\end{array}$ & Acetate & $\begin{array}{l}\text { Complex mixed } \\
\text { culture }\end{array}$ & 28.2 & {$[21]$} \\
\hline Single MFC & Spherical MFC/Nanocure ${ }^{\circledR}$ & CEM & $\begin{array}{l}\text { Air-breathing } \\
\text { (MPL) }\end{array}$ & $\begin{array}{l}\text { Neat human } \\
\text { urine }\end{array}$ & $\begin{array}{l}\text { Complex mixed } \\
\text { culture }\end{array}$ & 28.5 & {$[22]$} \\
\hline Single MFC & Rectangular MFC/Acrylic & CEM & $\begin{array}{l}\text { Air-breathing } \\
\text { (MPL) }\end{array}$ & Acetate & $\begin{array}{l}\text { Complex mixed } \\
\text { culture }\end{array}$ & 82.6 & $\begin{array}{l}\text { Unpublished } \\
\text { data }\end{array}$ \\
\hline Single MFC & Cylindrical thermoplastic & Ceramic & $\begin{array}{l}\text { Air-breathing } \\
\text { (MPL) }\end{array}$ & Acetate & $\begin{array}{l}\text { Complex mixed } \\
\text { culture }\end{array}$ & 81.5 & [23] \\
\hline \multicolumn{8}{|c|}{ Group 3} \\
\hline Single MFC & Rectangular MFC/ABS & CEM & Aerated water & $\begin{array}{l}\text { Synthetic } \\
\text { medium }+ \\
\text { lactate }\end{array}$ & S. oneidensis & 40 & [9] \\
\hline \multicolumn{8}{|c|}{ Group 4} \\
\hline Single MFC & Rectangular MFC/Nanocure ${ }^{\circledR}$ & CEM & $\begin{array}{l}\text { Air-breathing } \\
\text { (hydrated) }\end{array}$ & Acetate & $\begin{array}{l}\text { Complex mixed } \\
\text { culture }\end{array}$ & 26 & [3] \\
\hline Single MFC & Rectangular MFC/Acrylic & CEM & $\begin{array}{l}\text { Air-breathing } \\
\text { (hydrated) }\end{array}$ & Acetate & $\begin{array}{l}\text { Complex mixed } \\
\text { culture }\end{array}$ & 60 & [3] \\
\hline Single MFC & $\begin{array}{l}\text { Rectangular MFC/ } \\
\text { thermoplastic }\end{array}$ & CEM & $\begin{array}{l}\text { Air-breathing } \\
\text { (hydrated) }\end{array}$ & Acetate & $\begin{array}{l}\text { Complex mixed } \\
\text { culture }\end{array}$ & 802.5 & [3] \\
\hline \multicolumn{8}{|c|}{ Group 5} \\
\hline Single MFC & Tubular MFC/Nafion ${ }^{\circledR}$ & CEM & $\begin{array}{l}\text { Air-breathing } \\
\text { (hydrated) }\end{array}$ & Urine & $\begin{array}{l}\text { Complex mixed } \\
\text { culture }\end{array}$ & 0.124 & [19] \\
\hline Single MFC & Tubular MFC/Nafion ${ }^{\circledR}$ & CEM & $\begin{array}{l}\text { Air-breathing } \\
\text { (hydrated) }\end{array}$ & Urine & $\begin{array}{l}\text { Complex mixed } \\
\text { culture }\end{array}$ & 0.124 & {$[18]$} \\
\hline \multicolumn{8}{|c|}{ Group 6} \\
\hline Single MFC & Rectangular MFC/Nanocure ${ }^{\circledR}$ & CEM & $\begin{array}{l}\text { Air-breathing } \\
\text { (hydrated) }\end{array}$ & $\begin{array}{l}\text { Mixed complex } \\
\text { medium }\end{array}$ & $\begin{array}{l}\text { Complex mixed } \\
\text { culture }\end{array}$ & 26 & [20] \\
\hline Stack $n=48$ & Rectangular MFC/Nanocure $\mathbb{R}$ & CEM & $\begin{array}{l}\text { Air-breathing } \\
\text { (hydrated) }\end{array}$ & $\begin{array}{l}\text { Mixed complex } \\
\text { medium }\end{array}$ & $\begin{array}{l}\text { Complex mixed } \\
\text { culture }\end{array}$ & 1260 & {$[20]$} \\
\hline \multicolumn{8}{|c|}{ Group 7} \\
\hline Single MFC & Cylindrical MFCs/ceramic & Ceramic & $\begin{array}{l}\text { Air breathing } \\
(\mathrm{MPL})\end{array}$ & Urine & $\begin{array}{l}\text { Complex mixed } \\
\text { culture }\end{array}$ & 97.6 & $\begin{array}{l}\text { Unpublished } \\
\text { data }\end{array}$ \\
\hline $\begin{array}{l}\text { MFC module } \\
\mathrm{n}=22\end{array}$ & Cylindrical MFCs/ceramic & Ceramic & $\begin{array}{l}\text { Air breathing } \\
\text { (MPL) }\end{array}$ & Urine & $\begin{array}{l}\text { Complex mixed } \\
\text { culture }\end{array}$ & 4,150 & $\begin{array}{l}\text { Unpublished } \\
\text { data }\end{array}$ \\
\hline
\end{tabular}




\begin{tabular}{|l|l|l|l|l|l|l|l|}
\hline \multicolumn{9}{|c|}{ Group 8 } \\
\hline $\begin{array}{l}\text { MFC module } \\
\mathrm{n}=21\end{array}$ & $\begin{array}{l}\text { Carbon electrode MFCs } \\
\text { /thermoplastic }\end{array}$ & Membraneless & $\begin{array}{l}\text { Air breathing } \\
\text { (MPL) }\end{array}$ & Urine & $\begin{array}{l}\text { Complex mixed } \\
\text { culture }\end{array}$ & 5,650 & {$[24]$} \\
\hline $\begin{array}{l}\text { MFC module } \\
\mathrm{n}=38\end{array}$ & $\begin{array}{l}\text { Carbon electrode MFCs } \\
\text { /thermoplastic }\end{array}$ & Membraneless & $\begin{array}{l}\text { Air breathing } \\
\text { (MPL) }\end{array}$ & Urine & $\begin{array}{l}\text { Complex mixed } \\
\text { culture }\end{array}$ & 12,600 & {$[24]$} \\
\hline
\end{tabular}

